\title{
RENDIMENTO DA POLPA E CARACTERÍSTICAS QUÍMICAS DE FRUTAS NATIVAS COM POTENCIAL PARA CONSUMO HUMANO
}

\author{
Lorena Abdalla de Oliveira Prata Guimarães ${ }^{1}$ \\ André Angelo Bellon ${ }^{2}$ \\ Raiza Rainha Dorzenoni ${ }^{3}$ \\ Marianna Abdalla Prata Guimarães ${ }^{4}$ \\ Marilene Davel Dariva ${ }^{5}$
}

\begin{abstract}
Resumo: Com o intuito de ampliar o conhecimento sobre o potencial de consumo de frutíferas nativas não tradicionais na alimentação humana, este trabalho teve como objetivo quantificar o rendimento da polpa e avaliar características químicas de três frutas nativas com potencial para alimentação humana. Uma delas já é amplamente conhecida e consumida no Brasil - a jabuticaba, Plinia jaboticaba. As outras duas são a Eugenia pyriformis (uvaia) e a Garcinia brasiliensis (bacupari-anão). As análises de rendimento da polpa, teor de sólidos solúveis totais (SST), pH, acidez titulável (AT), vitamina C e o cálculo do "ratio" (SST/AT) foram realizados em frutos frescos. A uvaia apresentou $R P$ e teor de vitamina $C$ superiores. O teor de sólidos solúveis totais (SST) e a "ratio" foram maiores para a jabuticaba. Das três espécies avaliadas, a uvaia é a que apresenta o maior potencial para agroindústrias de produção de polpa. Também é a que apresenta o maior teor de vitamina $C$, o que indica o potencial dos frutos para introdução na dieta alimentar.

Palavras-chave: Eugenia pyriformis; Garcinia brasiliensis; Frutas nativas; Vitamina C.
\end{abstract}

\footnotetext{
${ }^{1}$ Incaper/CRDR Centro Serrano, Brasil. E-mail: lorena.prata@hotmail.com.

2 Incaper/CRDR Centro Serrano, Brasil. E-mail: aa-bellon@hotmail.com.

${ }^{3}$ Incaper/CRDR Centro Serrano, Brasil. E-mail: raiza_rainha_vni@hotmail.com.

${ }^{4}$ Incaper/CRDR Centro Serrano, Brasil. E-mail: marianna.prata@hotmail.com

${ }^{5}$ Incaper/CRDR Centro Serrano, Brasil. E-mail: marilene.dariva@gmail.com
} 